\title{
Menopozal Semptom Yönetiminde Sarı Kantaron Kullanımı: Sistematik Derleme*
}

\author{
The Use of St. John's Wort In Menopausal Symptom Management: A Systematic Review \\ Tuğba Dündari, Belma Toptaş̧i, Zekiye Karaçam iii
}

'Arş. Gör. Aydın Adnan Menderes Üniversitesi, Hemşirelik Fakültesi, Doğum-Kadın Sağlığı ve Hastalıkları Hemşireliği AD https://orcid.org/0000-0002-6693-0820

iiAş̧. Gör. Aydın Adnan Menderes Üniversitesi, Hemşirelik Fakültesi, Doğum-Kadın Sağlığı ve Hastalıkları Hemşireliği AD https://orcid.org/0000-0003-2018-9392

iiiiProf. Dr. Aydın Adnan Menderes Üniversitesi, Sağlık Bilimleri Fakültesi, Ebelik Bölümü https://orcid.org/0000-0002-0419-8961

öz

Amaç: Bu araştırma, menopoz döneminde kullanılan sarı kantaron bitkisinin menopozal semptomlara etkisini incelemek amacı ile yapılmıştır.

Yöntem: Sistematik derleme niteliğinde olan çalışma, 17 Aralık 2018-3 Ocak 2019 tarihleri arasında, Türkçe ve İngilizce dizinler taranarak yapılmıştır. Ulakbim, Türk Medline, Google Akademik ve Ulusal Tez Merkezi Web of Science, PubMed (including MEDLINE), Cochrane ve EBSCOhost veri tabanları, "menopoz, klimakteriyum, sarı kantaron, St John's wort, Hypericum perforatum, menopoz ve sarı kantaron, menopoz ve St John's wort, menopoz ve Hypericum perforatum, klimakteriyum ve sarı kantaron, klimakteriyum ve St John's wort, klimakteriyum ve Hypericum perforatum" anahtar kelimeleri ile taranmıştır.

Bulgular: Çalışmada toplam 602 kayda ulaşılmış olup, üçü sarı kantaronun tek başına, dördü farkıı bitkilerle bir arada kullanımının menopozal semptomlara etkisini inceleyen, toplam 819 kadın ile yapılan dokuz araştırma analize alınmıştır. Sarı kantaronun tek başına kullanıldığı beş çalışmadan ikisinde, bu bitkinin vazomotor semptomları, ikisinde uyku sorunlarını, depresyon ve yorgunluğu azaltmada etkili olduğu bildirilmiştir. Bitkinin kombine kullanıldığı dört çalışmadan üçünde kombinasyonun vazomotor semptomları, ikisinde anksiyete ve depresyonu azaltmada etkili olduğu, birinde ise vajinal kuruluk ve libido kaybı üzerinde herhangi bir etkisinin olmadığı bildirilmiştir.

Sonuç: Bu sistematik derlemede sarı kantaronun tek başına ya da kombine kullanımının bazı menopozal semptomları azaltmada etkili olduğu, ancak bu konuda daha fazla deneysel çalışmaya gereksinim bulunduğu sonucuna varılmıştır.

Anahtar Kelimeler: Sarı kantaron (hypericum), menopoz, tamamlayıcı tedaviler

\section{ABSTRACT}

Aim: The study aimed to investigate the effect of St. John's wort on menopausal symptoms.

Method: This study is a systematic review and was conducted between 17 December 2018-3 January 2019 by searching Turkish and English indexes. Ulakbim, Turk Medline, Google Academic and National Thesis Centre, Web of Science, PubMed (including MEDLINE), Cochrane and EBSCOhost database were searched by using "Menopause, climacterium, St. John's wort, Hypericum perforatum, menopause and St. John's wort, menopause and St John's wort, menopause and Hypericum perforatum, climacterium and St. John's wort, climacterium and Hypericum perforatum"as keywords.

Results: In this research, a total of 602 records were reached, and seven researches were analysed with 819 women, three of which examined the effect of the use of the St. John's wort singly and four in combination with different herbs on menopausal symptoms. In two of the three studies using the St. John's wort singly, this plant has been reported to be effective in reducing vasomotor symptoms, sleeping problems, depression/fatigue in two. In three of four studies used in combination of plant, was reported to be effective in reducing vasomotor symptoms, both anxiety and depression in two, and in one, it had no effect on vaginal dryness and loss of libido.

Conclusion: In this systematic review, it has been concluded that the use of St. John's wort singly or in combination is effective in reducing some menopausal symptoms, but further experimental studies are needed.

Keywords: hypericum, menopause, complementary therapies

${ }^{*}$ Lokman Hekim Dergisi, 2020; 10 (2): 258-268

DOI: $10.31020 /$ mutftd.688744

e-ISSN: 1309-8004

Geliş Tarihi - Received: 13 Şubat 2020; Kabul Tarihi - Accepted: 11 Mayıs 2020

iletişim - Correspondence Author: Tuğba Dündar <tugbadndr@gmail.com> 


\section{Giriş}

Menopoz, kadınların üreme dönemi sonunda ortaya çıkan, overlerin fonksiyon kaybı ve menstruasyonun kesilmesi ile karakterize bir süreçtir. ${ }^{1}$ Bu süreç kadın yaşamının özellikle fiziksel, psikolojik ve sosyal boyutlarını uzunca bir süre olumsuz etkileyebilir. ${ }^{2,3}$ Menopoz döneminde çoğu kadında östrojen hormonunun düşüşüne bağlı olarak vazomotor semptomlar, duygulanım bozuklukları ve ürogenital şikâyetler görülebilir. İlerleyen yıllarda ise östrojen kaybı sonucu kardiyovasküler hastalıklar, kemik kütlesi kaybı ve bilişsel bozukluk görülme sıklığında artış görülebilir. ${ }^{1}$ Günümüzde kadınlar, bu dönemin uzun sürmesi ve yaşam süresinin uzaması nedenleri ile sağılıkı yaşam ve yaşam kalitelerini artırabilecek tamamlayıcı sağıı yaklaşımları arayışı içindedir. ${ }^{4}$ Tamamlayıcı sağlık yaklaşımları vitamin, mineral ve bitkisel ürünlerin kullanımından yoga, meditasyon ve homeopati kullanımına kadar geniş bir yelpazede yer almaktadır. ${ }^{5}$ Tamamlayıcı sağlık yaklaşımlarının kullanım nedenleri, sağılı sorunları üzerine etkileri, bireydeki etkileri ve yan etkileri kişiden kişiye farklılık gösterebilir. Bu bağlamda menopoz döneminde tıbbi tedavilerin dışında yararlanılabilecek tamamlayıcı sağlık yaklaşımları kullanımının araştırıması, gerekli ve önemli bir konudur.

Sarı kantaron (St. John's wort/Hipericum perforatum), dünyanın pek çok yerinde, yol kenarlarında kendi başına büyüyebilen, uzun ömürlü ve altın sarısı renkte çiçekleri olan bir bitkidir. Bu bitki, tıpta birçok alanda uzun yıllardır kullanılmakta olup, özellikle doğal bir antidepresan olduğu bilinmektedir. Ayrıca sarı kantaron, uyku sorunlarının giderilmesinde, yara ve yanık tedavisinde ve menopozal semptomların azaltılmasında kullanılmaktadır. ${ }^{6,7}$

Literatürde sarı kantaronun, menopozal semptomların yönetiminde farklı dozlarda, tek başına ya da farklı bitkilerle kombine kullanıldığı çalışmalar mevcuttur. ${ }^{8-13}$ Menopoz dönemindeki kadınlarla yapılan bazı çalışmalar, sarı kantaron bitkisinin sıcak basması, gece terlemesi, uyku sorunları ve anksiyete gibi semptomları azaltabildiğini rapor etmiştir. ${ }^{8-11}$ Ayrıca, sarı kantaronun farklı bitkilerle bir arada kullanımının menopozal semptomlara etkisi ile ilgili sistematik derlemeler de bulunmaktadır. Bu derlemelerde sarı kantaronun karayılan otu ya da keten tohumu ile birlikte kullanımın menopozal semptomların yönetiminde etkili olduğu sonuçları rapor edilmiştir. ${ }^{11,14,15}$ Ancak güncel orijinal araştırmaların da dahil edildiği, sarı kantaronun tek başına ya da farklı bitkilerle kombine kullanımının menopozal semptomlara etkisinin incelendiği daha kapsamlı bir çalışmaya gereksinim bulunmaktadır. Bu sistematik derlemede menopoz döneminde kullanılan sarı kantaron bitkisinin menopozal semptomlara etkisinin belirlenmesi amaçlanmıştır. Bu amaç doğrultusunda i) Sarı kantaronun tek başına kullanımının menopozal semptomlara etkisi nedir? ii) Sarı kantaronun farklı bitkilerle kombine kullanımının menopozal semptomlara etkisi nedir? Sorularına yanıt aranmıştır. Elde edilen verilerin, mevcut ulusal ve uluslararası literatüre, bu konudaki sağlık hizmeti uygulamalarına ve gelecekte yapılması planlanan bilimsel çalışmalara katkı sağlaması beklenmektedir.

\section{YÖNTEM}

Bu çalışma sistematik derleme niteliğindedir. Çalışmanın yapılması ve raporunun hazırlanmasında Sistematik Derleme ya da Meta Analiz Araştırma Raporunun Yazımında Bulunması Gereken Maddelerle Illgili Kontrol Listesi (PRISMA) protokolü takip edilmiştir. ${ }^{16,17}$ Bu sistematik derlemede olası bias riskini azaltmak için literatür tarama, makale seçimi, veri çekme ve makale kalitesinin değerlendirilmesi işlemleri bir ve ikinci araştırmacılar tarafından bağımsız olarak yapılmış, her bir aşama üçüncü araştırmacının da katıldığı bir oturumda kontrol edilmiş ve görüş birliği oluşturulmuştur. Sürecin uygun biçim ve kalitede gerçekleştirilebilmesi için üç araştırmacının bir arada olduğu bir oturumda, çalışmanın kapsamında yer alan bir anahtar kelime (St John's wort and menopause) ile PubMed tarama motoru üzerinden tarama yapma, makale seçme, beş araştırma makalesi ile veri çekme ve makale kalitesini değerlendirme işlemlerini 
kapsayacak biçimde pilot çalışma yapılmıştır. Pilot çalışma sonrası ortaya çıkan görüş ve bilgi farklııkları tartışma yolu ile giderilmiş̧ir.

\section{Tarama Stratejisi}

Bu sistematik derleme için taramalar 17 Aralık 2018-3 Ocak 2019 tarihleri arasında yapılmıs ve yayın sürecinde son yayınların da dâhil edilmesi amacı ile Nisan 2020'de güncellenmiştir. Taramalar, ulusal düzeydeki yayınlara ulaşmak için “menopoz, klimakteriyum, sarı kantaron, St John's wort, Hypericum perforatum, menopoz ve sarı kantaron, menopoz ve St John's wort, menopoz ve Hypericum perforatum, klimakteriyum ve sarı kantaron, klimakteriyum ve St John's wort, klimakteriyum ve Hypericum perforatum" anahtar kelimeleri ile Ulakbim, Türk Medline, Google Akademik ve Ulusal Tez Merkezi arama motorları üzerinden yapılmıştır. Uluslararası yayınlara ise "menopause, climacterium, St John's wort, Hypericum perforatum, menopause and St John's wort, climacterium and St John's wort, menopause and Hypericum perforatum, climacterium and Hypericum perforatum" anahtar kelimeleri kullanılarak Web of Science, PubMed (including MEDLINE), Cochrane ve EBSCOhost veri tabanları üzerinden tarama yapılarak ulaşılmıştır. İlave çalışmaların elde edilmesi için dâhil edilen araştırmaların kaynaklar listesi incelenmiştir.

\section{Araştırmaların Seçim Kriterleri ve Seçimi}

Bu sistematik derleme için uygun olan araştırmalar aşağıdaki dâhil etme kriterlerine göre seçilmiştir;

(1) Çalışma grubu: Menopoz dönemindeki kadınlar.

(2) Müdahale: Sarı kantaron kullanma.

(3) Karşılaştırma: Sarı kantaron kullanmama.

(4) Sonuçlar: Menopozal semptomlar.

(5) Çalışma dizaynı: Deneysel ve yarı deneysel çalışmalar.

Çalışmadan dışlama kriterlerini Yöntemi belli olmayan, tam metnine ulaşılamayan, gözlemsel ya da hayvan deneyleri olan ve sarı kantaronun menopoz dışında kullanıldığı alanlarda yapılan çalışmalar oluşturmuştur.

Bu sistematik derleme için sarı kantaronun sadece menopozda kullanımını ele alan araştırmalara seçilmiştir. Araştırmaların belirlenmesi ve seçimi dâhil etme kriterlerine uygun olarak, birinci ve ikinci araştırmacı tarafından bağımsız olarak yapılmıştır. Taramalarda tekrar eden araştırmalar çıkarıldıktan sonra, sırası ile başlık, özet ve tam metne göre seçim yapılmıştır. Sistematik derlemede takip edilen seçim süreci Şekil 1'de verilmiştir.

\section{Veri Çekilmesi}

Araştırmada verilerin elde edilmesi için araştırmacılar tarafından geliştirilen bir veri çekme aracı kullanılmıştır. Bu veri çekme aracı ile araştırmaların yazar ve yayın yılı, yöntemi, örneklem hacmi, vaka sayısı, yapıldığı ülke, verilerin toplandığı yıl, yaş ortalaması, müdahale türü ve menopoz dönemine etkisi hakkındaki verilerin elde edilmesi sağlanmıştır.

\section{Çalışmaların Metodolojik Kalitesinin Değerlendirilmesi}

Bu sistematik derlemeye dâhil edilen araştırmaların metodolojik kalitesi Joanna Briggs Institute tarafından yayınlanan kontrol listeleri ile değerlendirilmiştir. ${ }^{18}$ Buna göre randomize kontrollü araştırmaların kalite değerlendirmesi 13 maddeli ${ }^{19}$ ve yarı deneysel çalışmalar dokuz maddeli ${ }^{20}$ kontrol listeleri ile yapılmıştır. Bu listelerde yer alan her madde "evet, hayır, belirsiz ve uygulanmaz" olarak değerlendirilmektedir. Her bir araştırma için saptanan durum Tablo 1 ve 2'de verilmiştir. 
Tablo 1. Sistematik derlemeye dâhil edilen sarı kantaronun tek başına kullanıldığı deneysel araştırmaların özellikleri ve sonuçları

\begin{tabular}{|c|c|c|c|c|c|c|c|c|c|c|}
\hline Yazarlar (yıl) & $\begin{array}{l}\text { Çalışma } \\
\text { deseni }\end{array}$ & $\begin{array}{l}\text { Veri toplama } \\
\text { aracı }\end{array}$ & Ülke & $\begin{array}{l}\text { Sarı } \\
\text { Kantaron } \\
\text { dozu }\end{array}$ & $\begin{array}{l}\text { Örneklem } \\
\text { hacmi }\end{array}$ & $\begin{array}{l}\text { Yapıldığı } \\
\text { yıl }\end{array}$ & $\begin{array}{l}\text { Ortalama yaş, } \\
\text { yıl (SS) }\end{array}$ & Grup Özelliği & Başlıca Sonuçlar & Kalite puanı \\
\hline $\begin{array}{l}\text { Abdali ve ark. } \\
2010\end{array}$ & $\begin{array}{l}\text { Randomize, } \\
\text { çiftkör, } \\
\text { placebo } \\
\text { kontrollü } \\
\text { klinik } \\
\text { çalş̧ma }\end{array}$ & $\begin{array}{l}\text {-AssessmentTool } \\
\text { OfClimacteric } \\
\text { Symptoms } \\
\text {-Blatt- } \\
\text { Kupperman } \\
\text { Index }\end{array}$ & İran & $\begin{array}{c}3 \times 20 \\
\text { damla/2ay }\end{array}$ & $\begin{array}{c}\text { San } \\
\text { kantaron: } \\
(n=45) \\
\text { Plasebo } \\
(n=43)\end{array}$ & 2008 & $\begin{array}{c}\text { San kantaron: } \\
50.5 \pm 3.7 \\
\text { Plasebo:50.29 } \\
3.52\end{array}$ & $\begin{array}{l}\text { Preperive } \\
\text { postmenopozal } \\
\text { dönem, enaz } 12 \\
\text { hafta boyunca } \\
\text { gündeen az bir } \\
\text { kezortaveya } \\
\text { şiddetlisıcak } \\
\text { basmasıyaşama }\end{array}$ & 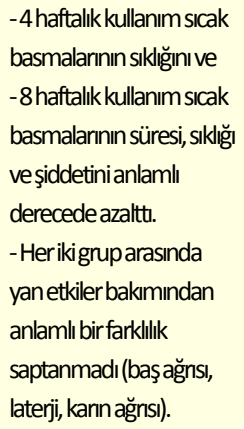 & $\begin{array}{l}\text { Evet:8/13 } \\
\text { Hayr:5/13 }\end{array}$ \\
\hline $\begin{array}{l}\text { Al-Akoumve } \\
\text { ark. } 2009\end{array}$ & $\begin{array}{l}\text { Randomize, } \\
\text { çiftkör, } \\
\text { placebo } \\
\text { kontrollü } \\
\text { pilotçalışma }\end{array}$ & $\begin{array}{l}\text {-Menopause- } \\
\text { Specific Quality of } \\
\text { Life(MENQOL) } \\
\text {-Sleep } \\
\text { Problem Scale } \\
\text { Multidimensional } \\
\text { Fatigue Inventory } \\
\text {-SF-12 }\end{array}$ & Kanada & $\begin{array}{l}\text { 3x300mgr } \\
/ 12 \text { hafta }\end{array}$ & $\begin{array}{c}\text { San } \\
\text { kantaron } \\
(n=20) \\
\text { Plasebo } \\
(n=22)\end{array}$ & $\begin{array}{l}2003- \\
2005\end{array}$ & $\begin{array}{c}\text { Sankantaron: } 53.4 \\
\quad \pm 4.8 \\
\text { Plasebo:54.0 } \pm 5.8\end{array}$ & $\begin{array}{l}\text {-Günde üçveya } \\
\text { daha fazla sıcak } \\
\text { basması, } \\
\text {-Enaz6ay } \\
\text { amenore }\end{array}$ & $\begin{array}{l}\text {-Günlüksıcak basma } \\
\text { sayısı ve sıcak basma } \\
\text { puanını azaltmada etkili } \\
\text { olmadı. } \\
\text { - Menopoza özgüyaşam } \\
\text { kalitesini anlamlı } \\
\text { derecedeartırdı. } \\
\text { - Uyku problemlerini, } \\
\text { vazomotorve } \\
\text { psikososyal semptomlan } \\
\text { anlamlı derecedeazalttı. } \\
\text { - Genel yorgunluğu, } \\
\text { cinsel ve fiziksel } \\
\text { semptomlarıetkilemedi. } \\
\text {-Her ikigrupta da } \\
\text { konstipasyonen sık } \\
\text { görülen yan etki olarak } \\
\text { belirlendi. }\end{array}$ & Evet:13/13 \\
\hline $\begin{array}{l}\text { Fahamiveark. } \\
2010\end{array}$ & $\begin{array}{l}\text { Yan } \\
\text { deneysel } \\
\text { çalışma }\end{array}$ & $\begin{array}{l}\text {-Personal Fertility } \\
\text { Features Quest. } \\
\text {-Cooperman's } \\
\text { index }\end{array}$ & İran & 3x160mgtb. & $\begin{array}{c}\text { San } \\
\text { kantaron } \\
(\mathrm{n}=30) \\
\text { Çarkffelek } \\
\text { çiçeği }(\mathrm{n}=29)\end{array}$ & - & $\begin{array}{c}\text { Sankantaron: } \\
51.7 \pm 3.3 \\
\text { Çarkfelek çiçeği: } \\
51.8 \pm 2.6\end{array}$ & $\begin{array}{l}\text {-Enfazla 5yldır } \\
\text { menopoz, } \\
- \text {-BKK<30 kg/cm } 2\end{array}$ & $\begin{array}{l}\text {-Menopozal } \\
\text { semptomları azaltmada } \\
\text { her iki bitki deetkili } \\
\text { bulundu. } \\
\text {-Uyku sorunları } \\
\text { azaltmada her iki bitki de } \\
\text { etkili bulundu. } \\
\text {-Bitkilerin birbirine } \\
\text { üstünlüğg̈ bulunmadı. }\end{array}$ & $\begin{array}{l}\text { Evet:7/9 } \\
\text { Hayr:2/9 }\end{array}$ \\
\hline $\begin{array}{l}\text { Ghazanfarpour } \\
\text { veark.2013 }\end{array}$ & $\begin{array}{l}\text { Randomize, } \\
\text { çiftkör, } \\
\text { kontrollü } \\
\text { çalışma }\end{array}$ & $\begin{array}{l}\text {-Green } \\
\text { Climacteric Scale }\end{array}$ & İran & $\begin{array}{l}\text { 3x160mg } \\
\text { tb/2ay } \\
\text { 3x1tb/2ay }\end{array}$ & $\begin{array}{c}\text { San } \\
\text { kantaron } \\
(n=37) \\
\text { Hayit }(n=39)\end{array}$ & 2013 & $\begin{array}{c}\text { San } \\
\text { kantaron:53.2 } \pm 4.7 \\
\text { Hayit: } 52.7 \pm 4.8\end{array}$ & $\begin{array}{l}\text {-45-65yaşarası } \\
\text {-Son } 1 \text { yldır } \\
\text { amenore }\end{array}$ & $\begin{array}{l}\text {-Her ikigupta da ölçek } \\
\text { puanı azaldı. } \\
\text {-Sıcak basmalanı her iki } \\
\text { grupta da azaldı. } \\
\text {-Bitkilerin birbirine } \\
\text { üstünlüğg̈ bulunmadı. } \\
\text {-Her iki gnup arasında yan } \\
\text { etkiler bakımından } \\
\text { anlamlı birfarklllık } \\
\text { saptanmadı (başağnsı, } \\
\text { laterji, karın ağnıı). }\end{array}$ & $\begin{array}{l}\text { Evet: } 6 \\
\text { Hayr: } 4 \\
\text { Belirsiz: } 3\end{array}$ \\
\hline $\begin{array}{l}\text { Eatemadniave } \\
\text { ark. } 2019\end{array}$ & $\begin{array}{l}\text { Randomize, } \\
\text { çiftkör, } \\
\text { kontrollü } \\
\text { çalışma }\end{array}$ & $\begin{array}{l}\text { - Kupperman } \\
\text { Index } \\
\text { - Hamilton } \\
\text { Depression } \\
\text { Rating Scale }\end{array}$ & İran & $\begin{array}{l}3 \times 270-330 \\
\mu g \text { tb/2ay } \\
3 x 1 \text { tb/2ay }\end{array}$ & $\begin{array}{c}\text { San } \\
\text { kantaron } \\
(n=35) \\
\text { Plasebo } \\
(n=35)\end{array}$ & - & $\begin{array}{c}\text { Sankantaron: } \\
50.4 \pm 2.7 \\
\text { Plasebo: } 50.6 \pm 2.8\end{array}$ & $\begin{array}{l}\text {-45-60yaşarası } \\
\text {-Son1 yldır } \\
\text { amenore } \\
\text { - Kooperman } \\
\text { IndeXinegöre en } \\
\text { azikimenopoz } \\
\text { belirtisi }\end{array}$ & $\begin{array}{l}\text {-4haftalık kullanım sıcak } \\
\text { basmalarının sıkığını } \\
\text { şiddetinianlamlı } \\
\text { derecedeazalttı. } \\
\text { - Bitki ölçek puanında4,6 } \\
\text { ve8. haftada anlamlı } \\
\text { azalma sağladı. }\end{array}$ & $\begin{array}{l}\text { Evet: } 12 \\
\text { Hayr: } 1\end{array}$ \\
\hline
\end{tabular}


Tablo 2. Sistematik derlemeye dâhil edilen sarı kantaronun kombine kullanıldığı deneysel araştırmaların özellikleri ve sonuçları

\begin{tabular}{|c|c|c|c|c|c|c|c|c|c|c|}
\hline $\begin{array}{l}\text { Yazarlar } \\
\text { (yıl) }\end{array}$ & $\begin{array}{l}\text { Çalışma } \\
\text { deseni }\end{array}$ & $\begin{array}{l}\text { Veri } \\
\text { toplama } \\
\text { aracı }\end{array}$ & Ülke & $\begin{array}{l}\text { Kombine } \\
\text { Kullanım } \\
\text { dozu }\end{array}$ & $\begin{array}{l}\text { Örneklem } \\
\text { hacmi }\end{array}$ & $\begin{array}{l}\text { Yapıldığı } \\
\text { yıl }\end{array}$ & $\begin{array}{l}\text { Ortalama } \\
\text { yaş, yıl (SS) }\end{array}$ & Grup Özelliği & $\begin{array}{l}\text { Başlıca } \\
\text { Sonuçlar }\end{array}$ & $\begin{array}{l}\text { Kalite } \\
\text { puanı }\end{array}$ \\
\hline $\begin{array}{l}\text { Chung ve } \\
\text { ark. } 2007\end{array}$ & $\begin{array}{l}\text { Randomiz } \\
\text { e, çift } \\
\text { kör, } \\
\text { placebo } \\
\text { kontrollü } \\
\text { çok } \\
\text { merkezli } \\
\text { çalışma }\end{array}$ & $\begin{array}{l}\text {-Vaginal } \\
\text { maturation } \\
\text { indices, } \\
\text { - } \\
\text { Kupperman } \\
\text { Index }\end{array}$ & Kore & $\begin{array}{l}12 \text { hafta } \\
\text { boyunca } \\
\text { Gyno-plus } \\
\text { (karayılan } \\
\text { otu ve sarı } \\
\text { kantaron) } \\
\text { tb. }\end{array}$ & $\begin{array}{l}\text { Tedavi grubu } \\
(n=42) \\
\text { Plasebo } \\
(n=35)\end{array}$ & $2005-2006$ & $\begin{array}{l}\text { Tedavi } \\
\text { grubu: } \\
51.02 \pm 3.48 \\
\text { Plasebo } \\
\text { grubu: } \\
50.43 \pm 2.81\end{array}$ & $\begin{array}{l}\text {-Tipik klimakterik } \\
\text { semptomlar } \\
\text { - En az } 3 \text { ay } \\
\text { hormon tedavisi } \\
\text { almama } \\
\text {-Perimenopozal } \\
\text { dönemde olma }\end{array}$ & $\begin{array}{l}\text {-Tedavi grubunda } \\
\text { sıcak basması } \\
\text { puanları } 4 \text {. ve } 8 . \\
\text { haftada azaldı. } \\
\text {-Kupperman } \\
\text { indexi } 4 \text {. ve } 8 . \\
\text { haftada tedavi } \\
\text { grubunda anlamlı } \\
\text { derecede azaldı. } \\
\text {-Vajinal kuruluk } \\
\text { ve libido } \\
\text { azalmasında } \\
\text { anlamlı gelişme } \\
\text { olmadı. } \\
\text {-Her iki grupta da } \\
\text { yan etkiler } \\
\text { benzerdir. }\end{array}$ & $\begin{array}{l}\text { Evet:7/13 } \\
\text { Hayır:5/13 } \\
\text { Belirsiz: } \\
\text { 1/13 }\end{array}$ \\
\hline $\begin{array}{l}\text { van Die } \\
\text { ve ark. } \\
2009\end{array}$ & $\begin{array}{l}\text { Randomiz } \\
\text { e, çift } \\
\text { kör, } \\
\text { placebo } \\
\text { kontrollü } \\
\text { paralel } \\
\text { çalışma }\end{array}$ & $\begin{array}{l}\text {-Abraham's } \\
\text { Menstrual } \\
\text { Symptoms } \\
\text { Questionna } \\
\text { ire }\end{array}$ & Avustralya & $\begin{array}{l}5400 \\
\text { mgr/gün } \\
\text { sarı } \\
\text { kantaron+ } \\
1000 \text { mg } \\
\text { hayıt/günd } \\
\text { e } 2\end{array}$ & $\begin{array}{l}\text { Tedavi grubu } \\
(n=8) \\
\text { Plasebo } \\
\text { grubu }(n=6)\end{array}$ & --------- & $\begin{array}{l}\text { Her iki } \\
\text { grubun da } \\
\text { yaş } \\
\text { ortalaması } \\
49\end{array}$ & $\begin{array}{l}\text {-Son } 12 \text { haftada } \\
\text { en az bir kez adet } \\
\text { görme } \\
\text {-Geç } \\
\text { perimenopozal } \\
\text { dönemde olma }\end{array}$ & $\begin{array}{l}\text {-16 haftalık } \\
\text { tedavi sonunda } \\
\text { anksiyete ve } \\
\text { hidrasyon azaldı. } \\
\text {-Toplam PMS } \\
\text { benzeri skorlar } \\
\text { için plaseboya } \\
\text { üstün bulundu. }\end{array}$ & $\begin{array}{l}\text { Evet:8/13 } \\
\text { Hayır:5/13 }\end{array}$ \\
\hline $\begin{array}{l}\text { van Die } \\
\text { ve ark. } \\
2009\end{array}$ & $\begin{array}{l}\text { Randomiz } \\
\text { e, çift } \\
\text { kör, } \\
\text { placebo } \\
\text { kontrollü } \\
\text { paralel } \\
\text { çalışma }\end{array}$ & $\begin{array}{l}\text {-Greene } \\
\text { Climacteric } \\
\text { Scale } \\
\text {-Hamilton } \\
\text { Depression } \\
\text { Inventory } \\
\text {-Utian } \\
\text { Quality of } \\
\text { Life Scale }\end{array}$ & Avustralya & $\begin{array}{l}\text { Sarı } \\
\text { kantaron+ } \\
\text { hayıt/16 } \\
\text { hafta } \\
\text { günde } 2 \\
\text { kez }\end{array}$ & $\begin{array}{l}\text { Tedavi } \\
(n=50) \\
\text { Plasebo } \\
(n=50)\end{array}$ & 2004-2005 & $\begin{array}{l}\text { Tedavi } \\
\text { grubu: } \\
51.9 \pm 4.3 \\
\text { Plasebo } \\
\text { grubu: } \\
52.5 \pm 3.8\end{array}$ & $\begin{array}{l}\text {-Postmenopoz } \\
\text { veya geç } \\
\text { perimenopozda, } \\
-24 \text { saatte en az } \\
5 \text { sıcak basması } \\
\text { veya terleme } \\
\text { yaşama }\end{array}$ & $\begin{array}{l}\text {-Sıcak basmaları } \\
\text { ve ölçek } \\
\text { puanlarında } \\
\text { anlamlı bir fark } \\
\text { saptanmadı. } \\
\text {-Yaşam } \\
\text { kalitesinde ve } \\
\text { depresyonda } \\
\text { anlamlı değişiklik } \\
\text { olmadı. } \\
\text {-Her iki grupta da } \\
\text { yan etkiler } \\
\text { benzerdir. }\end{array}$ & $\begin{array}{l}\text { Evet:11/13 } \\
\text { Hayır:2/13 }\end{array}$ \\
\hline $\begin{array}{l}\text { Uebelhadk } \\
\text { veark. } \\
2006\end{array}$ & $\begin{array}{l}\text { Randomiz } \\
\text { e, çift } \\
\text { kör, } \\
\text { placebo } \\
\text { kontrollü } \\
\text { çalışma }\end{array}$ & $\begin{array}{l}\text { - } \\
\text { Menopause } \\
\text { Rating } \\
\text { Scale } \\
\text {-Hamilton } \\
\text { Depression } \\
\text { Rating } \\
\text { Scale }\end{array}$ & Almanya & $\begin{array}{l}\text { Sarı } \\
\text { kantaron+ } \\
\text { karayılan } \\
\text { otu } \\
2 \times 2 \text { tb/ilk } \\
8 \text { hafta, } \\
2 \times 1 \\
\text { tb/ikinci } 8 \\
\text { hafta }\end{array}$ & $\begin{array}{l}\text { Tedavi grubu } \\
(n=150) \\
\text { Plasebo } \\
(n=143)\end{array}$ & 2003-2004 & $\begin{array}{l}\text { Tedavi } \\
\text { grubu: } 52.4 \pm \\
4.5 \\
\text { Plasebo } \\
\text { grubu: } 51.9 \pm \\
4.0\end{array}$ & $\begin{array}{l}\text {-En az } 3 \text { ay } \\
\text { boyunca tedavi } \\
\text { edilmeyen } \\
\text { menopozal } \\
\text { şikayetleri olma }\end{array}$ & $\begin{array}{l}\text {-Ölçek } \\
\text { puanlarında hem } \\
8 \text { hem } 16 \\
\text { haftada anlamlı } \\
\text { azalma saptandı. } \\
\text {-Gruplar arasında } \\
\text { yan etkilerde fark } \\
\text { bulunmadı. }\end{array}$ & $\begin{array}{l}\text { Evet:8/13 } \\
\text { Hayır:5/13 }\end{array}$ \\
\hline
\end{tabular}




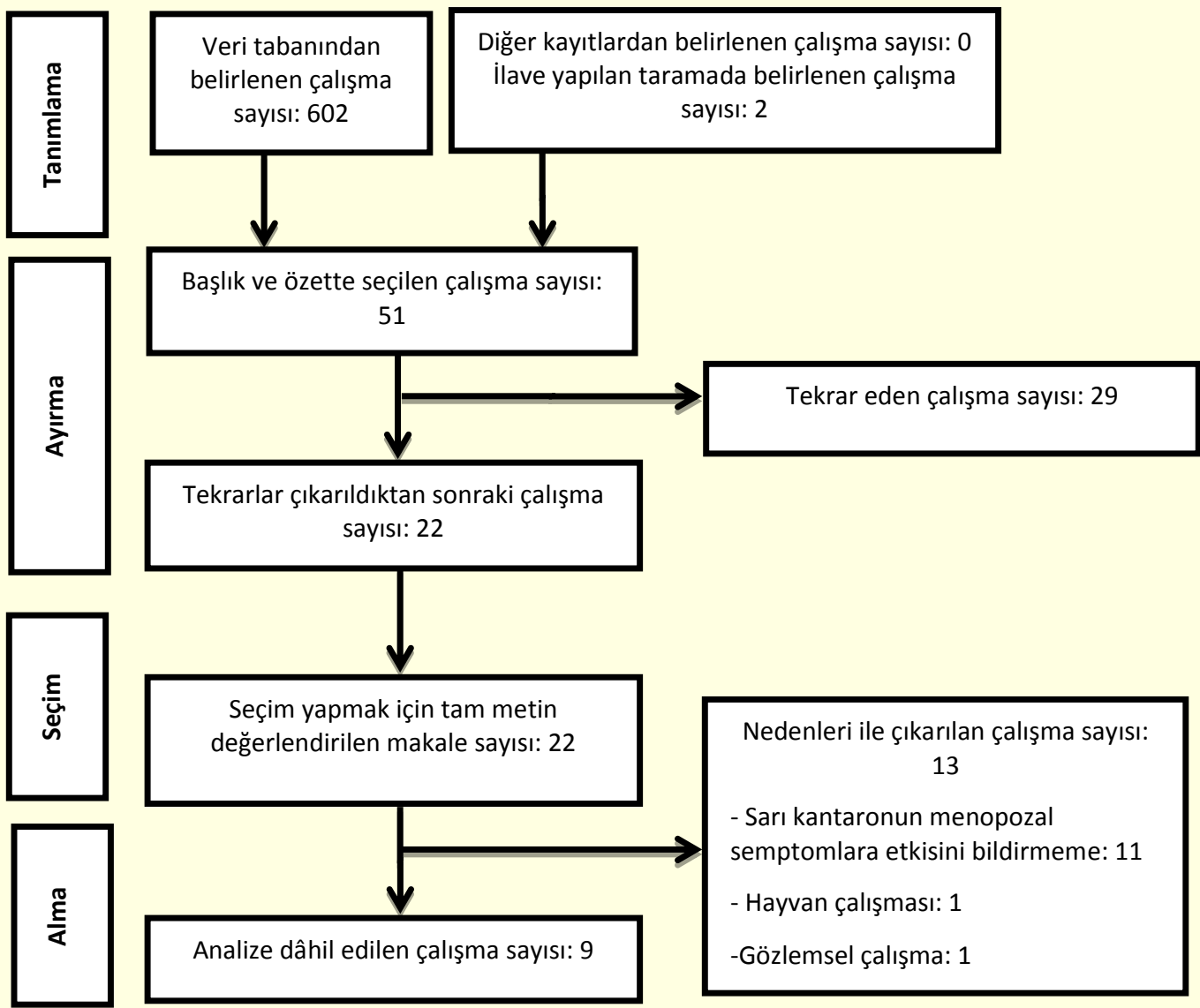

Şekil 1. Çalışmaların Seçimi ve Alma Süreci

\section{Verilerin Analizi}

Verilerin analizinde anlatı sentezi (narrative synthesis) yöntemi kullanılmıştır. Anlatı sentezi, hem nicel hem de nitel çalışmaları sentezlemek için kullanılabilen bir yöntemdir ve sistematik derlemeye dâhil edilen deneysel ve yarı deneysel çalışmaların bulguları meta-analiz yapılması için yeterince benzer olmadığında kullanılabilir. ${ }^{21,22}$ Bu sistematik derlemede incelenen araştırmaların deseni, sarı kantaronun kullanım şekli, dozu ve süresi, gözlenen menopozal semptomlar ve veri toplama yöntemleri farklılık göstermekte idi. Bu nedenle bulgular öyküsel anlatım yöntemi ile sunulmuştur.

\section{BULGULAR}

Bu çalışmada veri tabanlarının taraması sonucunda toplam 602 kayda ulaşılışstır. Planlanan tarama stratejisi kullanılarak başlık ve özette seçim yapıldıktan ve tekrarlar çıkarıldıktan sonra 22 çalışma, tam metin olarak incelenmiştir. İncelenen çalışmaların 11 tanesi menopoza yönelik veri içermediği, biri hayvanlar üzerinde yapıldığı ve biri de gözlemsel çalışma olduğu için çıkarılmışır. Toplam dokuz makale analize alınmıştır. Analize alınan makalelerin beş tanesi sarı kantaronun tek başına, 8,9,12,13,23 dört tanesi de sarı kantaronun farklı bitkilerle kombine kullanımının menopozal semptomlara etkisini incelemiştir. ${ }^{10,24-26}$

Sistematik derlemeye alınan araştırmaların sekizi randomize kontrollü deneysel ve biri yarı deneysel özelliktedir. Çalışmalar İran (4), Kanada (1), Kore (1), Avustralya (2) ve Almanya (1)'da yapılmış ve toplam örneklem hacmi 819 olarak hesaplanmıştır (Tablo 1 ve 2). Analize dâhil edilen araştırmaların 2003-2019 yılları arasında yapıldığı ve yayınlandığı saptanmıştır. Çalışmalarda kullanılan veri toplama araçları, katılımcıların yaş ve grup özellikleri Tablo 1 ve 2'de sunulmuştur. Bu sistematik derlemeye dâhil edilen 
randomize kontrollü deneysel araştırmalar 13 maddelik kanıt kalitesi değerlendirme aracının 6-13 maddesini, yarı deneysel çalışma ise dokuz maddelik kanıt kalitesi değerlendirme aracının 7 maddesini "evet" olarak karşılamıştır (Tablo 1 ve 2).

\section{Sarı Kantaronun Tek Başına Kullanımını Ele Alan Çalışmalar}

Sarı kantaronun tek başına kullanıldığı beş çalışmada, bu bitkinin vazomotor semptomlar, uyku sorunları, depresyon ve yorgunluğa olan etkileri incelenmiştir. ${ }^{8,9,12,13,23}$ Bu konulardaki bulgular aşağıda sunulmuştur.

\section{Vazomotor semptomlar}

Bu grupta yer alan beş çalışmada da vazomotor semptomlara yönelik sonuçlara yer verildiği görülmüştür. 8,9,12,13,23 Çalışmalarda menopozal semptomların değerlendirilmesinde Blatt-Kupperman Index ${ }^{12}$, Menopause-Specific Quality of Life $^{8}$, Green Climacteric Scale ${ }^{13}$, Kupperman's index ${ }^{23}$ ve Cooperman's index ${ }^{9}$ kullanıldığı saptanmıştır. Çalışmalardan ikisi, sarı kantaron kullanımının sıcak basma sayısı, sıklığı ve şiddetini anlamlı derecede azalttığını göstermiştir. ${ }^{12,23}$ Abdali ve ark (2010) tarafından yapılan çalışmada iki ay boyunca günde $3 \times 20$ damla sarı kantaron kullanımının birinci ayın sonunda sadece sıcak basmasının şiddetini, ikinci ayın sonunda ise şiddeti ile birlikte süresini de anlamlı derecede azalttığı rapor edilmiştir. ${ }^{12}$ Eatemadnia ve ark ise çalışmalarında sarı kantaronun 3x 270-330 $\mu \mathrm{g}$ tb. formunun birinci ayın sonunda sıcak basması sıklığını anlamlı derecede azalttığını bildirmiştir. Ayrıca bitkinin Kupperman Index'ini yaklaşık 4 kat azalttığı (başlangıç puanı $26.09 \pm 6.82,8$ hafta sonunda $6.49 \pm 4.61$ ) belirlenmiştir. ${ }^{23}$

Sarı kantaronun sıcak basması üzerinde anlamlı etkisinin olmadığını bildiren çalışmaların birinde plasebonun ${ }^{8}$, diğerinde de çarkıfelek çiçeğinin ${ }^{9}$ kontrol grubu olarak kullanıldığı görülmüştür. Kanada'da AlAkoum ve ark.'nın 3 ay boyunca $3 \times 300$ mg/gün sarı kantaron kullanımının sonuçlarını değerlendirdiği randomize kontrollü çalışmada, plasebo grubu ile bitki kullanan grup arasında sıcak basmalarının sayısı ve şiddeti açısından anlamlı fark çıkmamasına rağmen, sarı kantaronun sıcak basmalarını en az 2 kat azalttığı ifade edilmiştir. ${ }^{8}$ Iran'da yapılan diğer iki çalışmada da her iki bitkinin de menopozal semptomları azaltmada etkili olduğu, ancak sarı kantaronun çarkıfelek çiçeğine (Passion flower) ${ }^{9}$ ve hayıta (Vitex agnus castus) $^{13}$ göre üstünlük sağlamadığı ortaya konulmuştur.

\section{Uyku sorunları}

Sarı kantaronun uyku sorunları üzerindeki etkisine değinen çalışmalardan biri sarı kantaron bitkisinin kullanımının uyku sorunları üzerinde olumlu etkiye sahip olduğunu bildirmiştir. ${ }^{8}$ Çarkıfelek çiçeğinin kontrol grubu olarak kullanıldığı diğer çalışmada her iki bitkinin de uyku sorunlarını azaltmada etkili olduğu, ancak sarı kantaronun kontrol grubundaki bitkiye göre üstünlüğünün olmadığı belirtilmiştir. ${ }^{9}$

\section{Depresyon ve yorgunluk}

Sistematik derlemeye dahil edilen çalışmalardan biri, sarı kantaronun tek başına kullanımının yorgunluğu azaltmada etkili olduğunu ${ }^{8}$, diğeri ise kontrol grubundaki bitkiyle birlikte sarı kantaronun da yorgunluğu azalttığını ortaya koymuştur. ${ }^{9}$ Bitkinin depresyon ile ilgili etkileri iki çalışmada değerlendirilmiştir. ${ }^{9,23}$ Çalışmaların birinde sarı kantaronun kontrol grubundaki plasebo ile arasında anlamlı bir farklıık saptanırken ${ }^{23}$, diğerinde her iki grupta da anlamlı azalma olduğ $\mathbf{u}^{9}$ rapor edilmiştir.

\section{Yan Etkiler}

Sarı kantaronun tek başına kullanıldığı üç çalışmada bitkinin yan etkilerinden bahsedilmiştir. Bu çalışmaların ikisinde bitkinin plasebo, ${ }^{8,14}$ birinde de hayıt ${ }^{15}$ ile benzer yan etkilere sahip olduğu ifade edilmiştir. En sık rapor edilen yan etkilerin letarji, baş ağrısı, abdominal ağrı, konstipasyon ve ağız kuruluğu olduğu belirtilmiştir. ${ }^{8,12,13}$ 


\section{Sarı Kantaronun Kombine Kullanımını Ele Alan Çalışmalar}

Bu sistematik derlemede analiz sonuçları sarı kantaronun kombine kullanıldığı dört farklı çalışmanın sonuçlarını içermektedir. ${ }^{10,24-26}$ Bu çalışmaların ikisinde sarı kantaron bitkisi karayılan otu (Black cohosh) ${ }^{24,25}$, diğer ikisinde de hayı ${ }^{10,26}$ ile birlikte kullanılmıştır.

\section{Vazomotor semptomlar}

Çalışmaların üçünde bu bitkinin kombine kullanımının vazomotor semptomlara etkisinin ele alındığı görülmüştür. ${ }^{24-26}$ Chung ve ark.'nın çalışmasında sarı kantaronun karayılan otu ile birlikte 12 hafta boyunca kullanımının sıcak basması puanını anlamlı derecede düşürdüğü ortaya koyulmuştur. Aynı kombine bitkinin vazomotor semptomların sübjektif değerlendirmesini sağlayan Kupperman Index'ini yaklaşık 4 kat azalttığı (başlangıç puanı $26.46 \pm 10.64,12$ hafta sonunda $6.37 \pm 4.16$ ) belirlenmiştir. ${ }^{24}$ Hayıt ve sarı kantaronun 16 hafta boyunca kombine kullanımının incelendiği diğer çalışmada ise bu kombinasyonun günlük sıcak basması puanlarını yaklaşık yarı yarıya azalttı̆̆ı, ancak bitkilerin birlikteliğinin plaseboya göre üstünlük sağlamadığı rapor edilmiştir. ${ }^{26}$ Bir diğer çalışmada ise karayılan otu ile sarı kantaronun bir arada 16 hafta boyunca kullanımının hem Menopause Rating Scale ölçeği toplam puanını hem de alt boyutu olan sıcak basması puanını anlamlı derecede azalttığı ifade edilmiştir. ${ }^{25}$

\section{Anksiyete ve Depresyon}

Dört çalışmanın üçünde ${ }^{10,25,26}$ sarı kantaronun diğer bitkilerle birlikte kullanımının anksiyete ve depresyon üzerindeki etkisinin incelendiği görülmüştür. Sarı kantaronun hayıt ${ }^{10}$ ve karayılan otu ${ }^{25}$ ile bir arada kullanımının ele alındığı iki çalışmada anksiyete ve depresyonu azaltmada etkili oldukları ortaya konulmuştur. Ayrıca bu çalışmalara göre kombine kullanım, Hamilton Depression Inventory ve Hamilton Depression Rating Scale puanlarında \%50'den daha fazla azalma sağlamıştı ${ }^{10,25}$

\section{Diğer Semptomlar}

Sarı kantaronun karayılan otu ile kombine kullanımının incelendiği çalışmalardan birinde ${ }^{24}$ vajinal kuruluk ve libido kaybı üzerine herhangi bir etkisinin olmadığı belirlenmiştir.

\section{Yan Etkiler}

Sarı kantaronun kombine kullanıldığı üç çalışmada kullanılan bitkilere ilişkin yan etkilerinden bahsedilmiştir. Bu çalışmaların üçünde de plasebo ile sarı kantaron kullanımının neden olduğu yan etkiler arasında anlamlı bir farklıık olmadığı belirtilmiştir. En sık rapor edilen yan etkiler ise gastrointestinal şikayetler, enfeksiyon ve şişkinliktir. ${ }^{10,24,26}$

\section{TARTIŞMA}

Sarı kantaronun tek başına ve kombine kullanımının menopozal semptomlara etkisinin incelendiği bu sistematik derlemede, bitkinin tek başına kullanımının menopozal dönemdeki uyku sorunlarını azalttığı, kombine kullanımının ise vazomotor semptomları azaltmada daha güçlü bir etkisinin olduğu saptanmıştır. Ayrıca menopoz döneminde görülen anksiyete ve depresyon gibi ruhsal sorunları azaltmada sarı kantaronun tek başına ya da kombine kullanımından faydalanılabileceği de belirlenmiştir.

Bu sistematik derlemede sarı kantaronun, tek başına kullanıldığı bir çalışmada ve kombine kullanıldığı iki çalışmada vazomotor semptomların sayı ve şiddetini azaltmada etkili olduğu bulunmuştur. Kombine kullanıldığı iki çalışmada da sarı kantaron ve karayılan otu birlikte kullanılmıştır. Mehrpooya ve ark. (2018) yaptığı çalışmada, karayılan otunun tek başına farklı dozlarda ve sürelerde kullanımının vazomotor semptomların azaltılmasında etkili olduğunu göstermişken ${ }^{27}$, plasebo ile karşılaştırıldığı bir çalışmada ve bir meta analizde bu etkinin gösterilemediği bildirilmiştir. ${ }^{28,29} \mathrm{Bu}$ sonuçlara göre vazomotor semptomların 
yönetiminde sarı kantaronunu tek başına ya da karayılan otu ile birlikte kullanılabileceği, ancak bu konuda daha kapsamlı deneysel çalışmalara gereksinim bulunduğu söylenebilir.

Uyku sorunları menopozal dönemde en sık görülen semptomlar arasında yer alır. Bu dönemde yaşanan sıcak basması, gece terlemeleri ya da duygu durum bozuklukları kadınların uyku sorunu yaşamalarına neden olmaktadır. ${ }^{30,31} \mathrm{Bu}$ çalışmada sarı kantaronun tek başına kullanımının uyku sorunlarını azaltmada olumlu etkiye sahip olduğu bulunmuştur. Ayrıca bu bitkinin uykuya etkisi ile ilgili yapılan bir klinik çalışmada da REM latansını artırdığı ifade edilmiştir. ${ }^{32}$ Bu sonuçlar, bir sağıık profesyoneli danışmanlığında doğru bir öykü alımı ve bilgilendirme ile menopoz dönemindeki kadınlarda uyku sorunlarının yönetiminde sarı kantaron bitkisinden yararlanılabileceğini göstermesi bakımından önemlidir.

Çalışmada elde edilen veriler, sarı kantaronun tek başına ve kombine kullanımının menopoz dönemindeki kadınların anksiyete, depresyon ve/veya yorgunluk semptomlarını azaltmada etkili olduğunu göstermektedir. Sarı kantaronun depresyon üzerine etkisi ile ilgili yapılan diğer meta analiz ve sistematik derlemelerde de bu bitkinin depresif belirtileri azalttı̆̆ı rapor edilmiştir. ${ }^{33,34}$ Yine sarı kantaronun hayıt ve karayılan otu ile bir arada kullanıldığı çalışmalarda da depresyon semptomlarını giderdiği gösterilmiştir. ${ }^{35,36}$ Bu bulgular, menopozal dönemdeki kadınlarda anksiyete ya da depresyon belirtilerinin hafifletilmesinde sarı kantarondan tek başına ya da kombine biçimde yararlanılabileceğini ortaya koymaktadır.

Bu sistematik derlemede sarı kantaronun tek başına ve kombine kullanımı ile ilgili yan etkilerinin placebo ile bezer olduğu belirlenmiştir. Daha önce yapılan çalışmalar da ise sarı kantaronun sağlıklı kadınlar tarafından iyi tolere edilebilen bir bitki olduğu bildirilmiştir. ${ }^{8,37}$ Ancak yine de bu bitkinin farmakovijilans raporlarının oldukça az olması nedeni ile kullanılan ilaçlarla etkileşimleri ile ilgili, özellikle kısıtlı tedavi ve güven aralığına sahip ilaçlarla birlikte kullanımına ilişkin endişeler rapor edilmektedir. ${ }^{38}$ Bu sonuçlar menopoz dönemindeki kadınların sarı kantaron kullanmaya başlamadan önce mutlaka hekimleri ile görüşmeleri ve varsa kullandıkları ilaçlarını bildirmeleri, sarı kantaronu doktorlarının kontrol ve denetimi altında kullanmaları gerektiğini göstermektedir.

Bu sistematik derlemeye dâhil edilen araştırmaların kanıt kalitelerinin oldukça iyi düzeyde olduğu saptanmıştır. Bu sonuç, çalışmaların ortaya koyduğu bilgilerin güvenilir olduğunu göstermesi bakımından değerlidir.

Bu sistematik derlemenin bazı sınırlılıkları bulunmaktadır. Bunlardan birincisi, sistematik derlemeye dâhil edilen çalışmaların çoğunda (4/9) sarı kantaronun başka bir bitki ile kombinasyonu kullanılmıştır. Bu durum, bu çalışmada sarı kantarona ilişkin ortaya koyulan sonuçları etkilemiş olabilir. Diğeri, sistematik derlemeye dâhil araştırmalarda sarı kantaronun menopozal semptomlar üzerine olan etkisi farklı ölçüm araçları ile değerlendirilmiş olmasıdır. Bu nedenle çalışmada sunulan sonuçlar, standart ölçüm araçları ile elde edilebilecek sonuçlardan ya da klinik uzmanların değerlendirme sonuçlarından farklı çıkma olasılığı mevcuttur.

\section{SONUÇ VE ÖNERILER}

Çalışmada sarı kantaronun tek başına kullanımının daha çok uyku sorunları ve depresyon, kombine kullanımın ise vazomotor semptomlar ve depresyon üzerine etkili olduğu, sonuçları elde edilmiştir. Ayrıca bitkinin plasebo ve hayıt ile benzer yan etkilere sahip olduğu görülmüştür. Menopoz döneminde sarı kantaronun da içinde yer aldığı bitkilerin gittikçe artan bir şekilde hormonlara alternatif olarak kabul edildiği ve insanların kullanımda istekli olduğu bilinmektedir. ${ }^{35}$ Ancak her bir bitkinin insan vücudu üzerinde yan etkilere neden olabileceği, mevcut durumda kullanılan ilaçlarla etkileşime girebileceği unutulmamalıdır. Bunlara dikkat edildiği takdirde, menopoz dönemindeki kadınların, sağlık çalışanlarının denetiminde, var olan semptomlarının türü ve şiddetine göre sarı kantaronu tek başına ya da başka bitkilerle birlikte 
kullanmaları önerilebilir. Sağlık profesyonellerinin bu kadınlara, sarı kantaronun kullanımı konusunda eğitim ve danışmanlık yapmaları gerekmektedir. Herhangi bir bitkinin kullanımına başlamadan önce ayrıntılı bir öykü alınmalı, kadının genel sağlık durumu ve kullandığı ilaçları değerlendirilmeli, bitkinin kullanım şekli, miktarı, süresi ve olası yan etkileri konularında bilgilendirme yapılmalı ve gerektiğinde ileri tetkik ve tedaviye yönlendirilmelidir. Buna ek olarak sağlık profesyonelleri sarı kantaron ile ilgili güncellenen bilgileri sürekli takip etmeleri de gereklidir. Ayrıca sarı kantaronun menopozal semptomlar üzerine olan etkisi ile ilgili daha fazla randomize kontrollü çalışmalara ve meta analizlere de gereksinim bulunmaktadır.

\section{Bítgi}

Araştırmayı destekleyen kurum-kuruluş bulunmamaktadır. Çıkar çatışması bulunmamaktadır.

\section{KAYNAKLAR}

1. Lamberts SWJ, Beld AW. Endocrinology and aging. In: Melmed S, Auchus RJ, Goldfie AB, Koening RJ, Rosen CJ. editors. Williams textbook of endocrinology. Elseiver; 2016. pp:1234-1251.

2. Şen E, Sevil Ü. Menopoz semptomlarında tamamlayıcı tedaviler. İstanbul Üniversitesi Florence Nightingale Hemşirelik Derg 2008;16(62):136-42.

3. Rajput V. Menopause and alternative therapy. Asian J. Nurs. Edu. Res 2012;2(3):158-60.

4. Taylor M. Complementary and alternative approaches to menopause. Endocrinol. Metab. Clin. North Am 2015;44(3):619-48.

5. National Center for Complementary and Integrative Health [Internet]. Complementary, Alternative, or Integrative Health: What's In a Name? (2018). [cited 2019 February 12] Available from: https://nccih.nih.gov/health/integrative-health.

6. Vukovic L. Basic health publications user's guide to st john's wort. 1st ed. Rosenberg C editor. North Bergen: Basic Health Pubilications; 2002.

7. Murray PB, Bongiorno MT. Hypericum perforatum (St. John's Wort). In: Pizzorno JE, Murray MT, editors. Textbook of natural medicine. Churchill Livingstone; 2013. pp: 838-841.

8. Al-Akoum M, et al. Effects of hypericum perforatum (st. john's wort) on hot flashes and quality of life in perimenopausal women: a randomized pilot trial. Menopause 2009;16(2):307-14.

9. Fahami $F$, et al. A comparative study on the effects of hypericum perforatum and passion flower on the menopausal symptoms of women referring to Isfahan city health care centers. Iran J Nurs Midwifery Res 2010;15(4):202-7.

10. van Die $M$, et al. Effects of a combination of hypericum perforatum and vitex agnus-castus on pms-like symptoms in lateperimenopausal women: findings from a subpopulation analysis. J. Altern. Complement. Med 2009;15(9):1045-8.

11. Laakmann E, et al. Efficacy of cimicifuga_racemosa,_hypericum_perforatum and agnus_castus in the treatment of climacteric complaints: a systematic review. Gynecol. Endocrinol 2012;28(9):703-9.

12. Abdali K, Khajehei M, Tabatabaee H. Effect of st john's wort on severity, frequency, and duration of hot flashes in premenopausal, perimenopausal and postmenopausal women: a randomized, double-blind, placebo-controlled study. Menopause 2010;17(2):326-31.

13. Ghazanfarpour $\mathrm{M}$, et al. Comparison the efficacy of hypericum perforatum and vitex agnus- castus in hot flushes : A doubleblinded randomized controlled trial. Chronic Diseases Journal 2013;1(2):67-73.

14. Ghazanfarpour $M$, et al. Effects of flaxseed and hypericum perforatum on hot flash, vaginal atrophy and estrogen-dependent cancers in menopausal women: a systematic review and meta-analysis. Avicenna J. phytomedicine 2016;6(3):273-83.

15. Liu Y, et al. Hypericum perforatum L. preparations for menopause: a meta-analysis of efficacy and safety. Climacteric 2014;17:325-35.

16. Karaçam Z. Sistematik derleme metodolojisi: sistematik derleme hazırlamak için bir rehber. Dokuz Eylül Üniversitesi Hemşirelik Yüksekokulu Elektron. Derg 2013;6(1): 26-33.

17. Moher D, et al. Preferred reporting items for systematic reviews and meta-analyses: The PRISMA Statement. PLOS Med 2009;6:1-5.

18. Joanna Briggs Institute[Internet]. Critical Appraisal Tools. (2018). [cited by 18.03.2019]

Available from: http://joannabriggs.org/research/critical-appraisal-tools.html

19. Tufanaru C, Munn Z, Aromataris E, Campbell J, Hopp L. Explanation for the critical appraisal tool for RCTs with individual participants in parallel groups. In: Aromataris E, Munn Z, editors. Joanna Briggs Institute Reviewer's Manual. The Joanna Briggs Institute. 2017a. pp:1-9.

20. Tufanaru C, Munn Z, Aromataris E, Campbell J, Hopp L. Explanation for the critical appraisal tool for Quasi-Experimental Studies (experimental studies without random allocation). In: Aromataris E, Munn Z, editors. Joanna Briggs Institute Reviewer's Manual. The Joanna Briggs Institute. 2017b.pp:1-7. 
21. Snilstveit B, Oliver S, Vojtkova, M. Narrative approaches to systematic review and synthesis of evidence for international development policy and practice. Journal of Development Effectiveness 2012;4(3):409-429.

22. Ryan R, Cochrane Consumers and Communication Review Group. Cochrane consumers and communication review group: data synthesis and analysis. Cochrane Consum. Commun. Rev. Gr. 2013;1-5.

23. Eatemadnia A, Ansari S, Abedi P, Najar S. The effect of Hypericum perforatum on postmenopausal symptoms and depression: A randomized controlled trial. Complement. Ther. Med 2019;45:109-113.

24. Chung D, et al. Black cohosh and st. john's wort (GYNO-Plus ${ }^{\circledR}$ ) for climacteric symptoms. Yonsei Med. J 2007;48(2):289-94.

25. Uebelhack R, et al. Black cohosh and st. john's wort for climacteric complaints: a randomized trial. Obstet. Gynecol 2006;107(2):247-55.

26. van Die $\mathrm{M}$, et al. Hypericum perforatum with vitex agnus-castus in menopausal symptoms: a randomized, controlled trial. Menopause 2009;16(1):156-63.

27. Mehrpooya $M$, et al. A comparative study on the effect of "black cohosh" and "evening primrose oil" on menopausal hot flashes. J Educ Health Promot 2018;7(36).

28. Newton KM, et al. Use of alternative therapies for menopause symptoms: results of a population-based survey. Obstet. Gynecol 2002;100(1):18-25.

29. Franco $O$, et al. Use of plant-based therapies and menopausal symptoms a systematic review and meta-analysis. Jama 2019;315(23):2554-63.

30. Timur S, Şahin NH. Menopoz ve uyku. Maltepe Üniversitesi Hemşirelik Bilim ve Sanatı Derg 2010;3(3):61-67.

31. Ulusoy MN, Kukulu K. Kadınlarda uyku sorunlarının menopoz ile ilişkisi. Gümüşhane Üniversitesi Sağlık Bilim Derg 2013;2(2):206-13.

32. Sharpley AL, et al. Antidepressant-like effect of hypericum perforatum (st john's wort) on the sleep polysomnogram. Psychopharmacology (Berl) 1998;139(3):286-7.

33. Apaydin EA et al. A systematic review of st. john's wort for major depressive disorder. Syst Rev 2016;5(1):148.

34. Ng QX, Venkatanarayanan N, Ho CYX. Clinical use of hypericum perforatum (st john's wort) in depression: a meta-analysis. J Affect Disord 2017;210(January):211-21.

35. Wuttke W, Seidlová-wuttke D. Black cohosh ( cimicifuga racemosa ) is a non-estrogenic alternative to hormone replacement therapy. Clin. Phytoscience 2015;1(1):12.

36. Niroumand M, Heydarpour F, Farzaei M. Pharmacological and therapeutic effects of vitex agnus - castus: a review. Pharmacogn Rev 2018;12(23):103-14.

37. Whiskey E, Werneke U, Taylor D. A systematic review and meta-analysis of hypericum perforatum in depression: A comprehensive clinical review. Int Clin Psychopharmacol 2001; 16(5):239-52.

38. Russo $\mathrm{E}$, et al. Hypericum perforatum: pharmacokinetic, mechanism of action, tolerability, and clinical drug-drug interactions. Phyther Res 2014;28(5):643-55. 